\title{
Karl Jaspers e a abordagem fenomenológica em psicopatologia
}

\author{
Adriano Carvalho Tupinambá Rodrigues
}

\section{Introdução}

Karl Jaspers (1883-1969) nasceu em Oldenburg, cidade alemã próxima ao litoral do Mar do Norte, numa família de classe média. Sua diligente mãe procedia de uma comunidade camponesa, assim como seu pai, um bem-sucedido advogado e diretor bancário. Também foi através do direito o primeiro contato de Jaspers com a universidade. Após breve passagem por aquele curso trocou-o pela medicina, graduando-se em Heidelberg em 1908. Havendo apresentado, desde a infância, saúde débil e limitadas capacidades físicas, a vida sempre lhe exigiu cuidadosa administração das atividades que desempenhava. Além da possibilidade de reunir seus interesses por ciências naturais e humanas numa única atividade, seu ingresso nos estudos em psiquiatria se deu, em 1909, também em função de crer que a atuação em psicopatologia - requerendo-lhe menos desgaste físico do que intelectual - seria sua melhor oportunidade de ter uma carreira plenamente prolífica (Jaspers, 1994; Hoenig, 1966). Como bem observado por Jenner et al. (1996), uma convergência singular de fatores - seu pendor filosófico, seu treinamento médico e sua saúde frágil - provavelmente responde por muito do que foi possível Jaspers desenvolver no campo da psicopatologia. Dificilmente um filósofo poderia dispor, para 
fundamentação de suas idéias, dos elementos empíricos acessíveis a Jaspers na Clínica Psiquiátrica Universitária de Heidelberg. Por outro lado, mesmo ao psiquiatra com maior sofisticação intelectual, as obrigações extenuantes da rotina não facultariam o tempo e a tranqüilidade suficientes ao desenvolvimento teórico aprofundado. Jaspers, sendo psiquiatra com inclinações filosóficas e dispondo, em razão de sua saúde frágil, do privilégio de selecionar para estudo extensivo apenas os casos que lhe aprouvessem, encontrava-se em posição ímpar ${ }^{1}$ (Jenner et al., 1996; Mundt, 1993).

Àquela época, nomes como Grühle, Wilmanns, Ramke e Mayer-Gross compunham corpo clínico e propiciavam o fecundo ambiente de debates na clínica psiquiátrica daquela universidade, essencial fonte de subsídios e contrapontos para desenvolvimento da psicopatologia de Jaspers. Chefiada por Franz Nissl, eminente histologista e neuropatologista - e ainda fortemente influenciada pelas ambições kraepelinianas de uma psiquiatria e psicologia científicas -, a instituição se caracterizava pela concentração de esforços em favor de uma abordagem somática dos distúrbios mentais (Jaspers, 1994; Mundt, 1993; Hoenig, 1966). Todavia, no que dizia respeito aos recortes conceituais das manifestações psico(pato)lógicas, Heidelberg se constituía por distintos grupos, empregando uma profusão de diferentes terminologias, cada uma servindo a uma concepção teórica e metodologia próprias. Sem razoável interface entre as mesmas, e sem a adequada crítica sobre os loci teóricos de cada uma dessas plataformas lingüísticas, em lugar dos benefícios do pluralismo metodológico que daí podia decorrer, o que era notável era o desacordo dogmático e a esterilidade das discussões (Jaspers, 1994).

Também era o tempo em que vigorava o Metodenstreit - o debate filosófico acerca da metodologia a ser empregada pelas ciências humanas. Entre as discussões relevantes, situava-se a disputa sobre ser possível ou válido, também para as ciências humanas, o modelo causalista-explicativo empregado pelas ciências naturais, ou se tão-somente um modelo histórico-compreensivo.

Neste terreno conceitualmente movediço e epistemologicamente indefinido (Metodenstreit) é que Jaspers, em 1911, foi solicitado por Wilmanns a escrever

1. A esta altura de sua vida, chegaria a ser ousado opinar se Jaspers seria melhor caracterizado como um psiquiatra com inclinações e perspicácia filosóficas - e que fez um uso instrumental destas características para abordar seu objeto de interesse, o psiquismo humano - ou se, em vez disso, seria prioritariamente um pensador, que apenas viu na psicopatologia um rico campo a explorar. Fato é que muitos dos elementos considerados por Jaspers durante sua atuação como psicopatólogo - o homem e sua essência, o psiquismo em sua totalidade, a empatia e a compreensibilidade - são também elementos centrais em sua ulterior filosofia existencialista. 


\section{$\begin{array}{lllllll}R & E & V & \text { I } & S & T & A\end{array}$ \\ LATINOAMERICANA \\ DE PSICOPATOLOGIA \\ F U N D A M E N T L L \\ ano VIII, n. 4, dez/2005}

uma “Psicopatologia geral”. Em 1913, aos seus trinta anos de idade, foi lançada sua obra magna, Allgemeine Psychopathologie (Psicopatologia geral).

Reconhecido o contexto em que foi concebida, torna-se evidente que o esforço que se lhe impunha à confecção daquela obra - e que lhe conferiu valor central na tradição psicopatológica - era, sobretudo, pela crítica metodológica e pela sistematização dos dados. Sua tarefa se compôs pelo mapeamento dos suportes conceituais e métodos vigentes, pelo exame de suas virtudes e limitações quando empregados individualmente; pela exploração dos domínios específicos de aplicação dos métodos mais "gerais" (causalista-explicativo e históricocompreensivo) e, finalmente, pela proposição de um modelo de psico(pato)logia que, na sua visão, poderia atender a aspirações científicas (Jaspers, 1994; Mundt, 1993).

Embora ele próprio tenha negado que Allgemeine Psychopathologie fosse uma obra de psicopatologia fenomenológica (Jaspers, 1994; 2000), explicando que concebe esta última apenas como uma dentre as plataformas metodológicas possíveis para a psicopatologia, é sobre tal ferramenta que reside a maior "novidade” apresentada naquela obra.

Apesar de Psicopatologia geral ser a fonte mais difundida sobre seu método fenomenológico entre os estudiosos de psicopatologia, nesta obra Jaspers discorre sobre o tema apenas de maneira bastante sucinta; em muitos aspectos, até duvidosa e vagamente sobre o que realmente quer dizer, oferecendo limitados subsídios para críticas ou explorações sobre o mesmo. Embora o autor se estenda, ali, no que concerne à descrição "fenomenológica” das experiências específicas, pouco se atém ao detalhamento quanto ao método. Estranhamente, não é tão amplamente conhecido o trabalho que publicara no ano anterior (1912), onde a fundamentação, a descrição e a aplicação do método fenomenológico à psicopatologia são mais esmiuçados. Com o título original de Die Phänomenologiche Forschungsrichtung in der Psychopathologie e publicado em Zeitschrift fur die Gesamte Neurologie und Psychiatrie, este texto de seminal importância para o correto entendimento da psicopatologia fenomenológica jasperiana foi traduzido para o inglês e publicado no British Journal of Psychiatry (1968) como The Phenomenological Approach in Psychopathology.

Num momento em que proliferam vozes de endosso a propostas com base fenomenológica para classificação, diagnóstico e tratamentos em psiquiatria (Kraus, 1999; 2003; Parnas \& Zahavi, 2002; Stanghellini, 2004), é um mais correto entendimento da fenomenologia jasperiana e um mais justo tratamento à mesma, que ora buscamos. Para tanto, a via que aqui empregamos é a apresentação de Phenomenological Approach in Psychopathology e a discussão das idéias no mesmo contidas. Além disso, com o fim de desfazer eventuais confusões, a proposta jasperiana de fenomenologia é, ainda, examinada em suas 
origens e contrastada às distintas noções atreladas ao termo e que com ela se confundem.

\section{A psicopatologia fenomenológica jasperiana}

A centralidade da questão metodológica na psicopatologia jasperiana é também evidente em The Phenomenological Approach in Psychopathology. Logo à introdução desse texto Jaspers expõe sua crítica ao foco da "psicologia objetiva”. $\mathrm{O}$ autor ressalta que, embora atendendo com menos restrições ao modelo científico naturalista, a abordagem exclusiva aos elementos sensíveis e mensuráveis exclui da psicologia e da psiquiatria exatamente o que nelas há de mais essencial: o psíquico. Não obstante, sua advertência não é menos incisiva quanto às limitações de determinadas abordagens da "psicologia subjetiva”. Se, por um lado, esta se encontra menos vulnerável à deturpação do objeto de investigação que afeta as abordagens "objetivas", por outro mostra-se menos propensa a oferecer informações que possam ser registradas como científicas. Segundo Jaspers, em sua tarefa de estudar os fenômenos psíquicos, e não meramente suas manifestações ou correspondentes externos, a "psicologia subjetiva" se depararia com o limitado alcance da utilização da empatia como instrumento. $\mathrm{O}$ autor reconhece que embora muitos, segundo suas próprias ambições, possam legitimamente se satisfazer com a apreensão imediata e intuitiva dos fenômenos psicológicos da terceira pessoa que a empatia oferece, esta não provê conhecimento explícito ou sistematizável. Isto porque, como entendida por Jaspers, a empatia ${ }^{2}$ não decorreria de processo consciente, deliberado ou dotado de pontos visíveis de ancoragem. Sobre as limitações inerentes à apreensão empática dos fenômenos psicológicos, e sobre o que seria cientificamente desejável, Jaspers escreve:

2. Aqui, o termo empatia tem um sentido preciso. Ela consiste, para Jaspers, na "atualização" ou representação, em primeira pessoa, da experiência de outrem. Tratar-se-ia de um compartilhamento intuitivo e não reflexivo da vivência psicológica do interlocutor. Neste sentido, uma importante distinção que se precisa reconhecer é a feita por Jaspers - tal qual por Weber - entre “empatia” e “compreensão empática”. Enquanto a primeira consistiria numa “compreensão da pura experiência” (algo como dizer: “Uhm... entendo o que você está passando”), não sendo derivada de uma captura deliberada nem do processamento consciente e programado das informações provindas da interação entre os indivíduos; a última seria a “compreensão da experiência tornada cognoscível” - delimitada, descrita e nomeada (Walker, 1995b). Esta “compreensão empática” seria o coroamento da fenomenologia, aliando dois elementos: um de natureza cognoscível e delimitadora; e o outro, seu “preenchimento”, de natureza psíquica e ainda propício à empatia. 


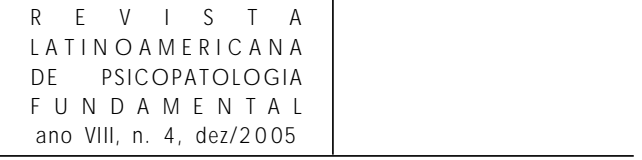

Assertions [empathic] of this sort cannot be discussed or verified. We may appreciate this type of understanding; we may admire it for the valuable human qualities which it reveals; but we can never give it recognition as a "science" (...). If, however we still wish to develop a science of psychology, we must realize from the start, on the one hand, that its ideal is a fully conscious understanding of mental processes, one that can be presented in definite terms and forms (...). (Jaspers, 1968, p. 1315)

Para Jaspers, a tarefa inicial da “psicologia subjetiva” deveria consistir precisamente em distinguir os fenômenos subjetivos, descrevê-los e nomeá-los. Somente assim, a abordagem à subjetividade deixaria de ser um mero compartilhamento de experiência para se tornar conhecimento sistematizável, comunicável e testável. Isto caracterizaria a própria fenomenologia, como concebia. Nesse texto, realçando as poucas e desarticuladas ações neste sentido, Jaspers sugere a psicopatologia descritiva ou fenomenologia como um programa frutífero e convoca às explorações na área.

Uma das preocupações da fenomenologia jasperiana, que se tornou mais conhecida, mesmo pelos não especialistas em psicopatologia, seria quanto ao desejável posicionamento pré-teórico e livre de pressuposições no processo descritivo.

... at this stage we must put aside altogether such considerations as the relationships between experiences, or their summation as a whole, and more especially must we avoid trying to supply any basic constructs or frames of reference. We should picture only what is really present in the patient's consciousness; anything that has not really presented itself to his consciousness is outside our consideration. (Jaspers, 1968, p. 1316)

Além de trabalhar apenas com os fenômenos realmente vividos pelos pacientes, propunha que a descrição e delimitação dos mesmos deveria ser realizada por meio de parâmetros exteriormente observáveis - modo de surgir, contexto de aparecimento, conteúdo etc. Jaspers não ignorava que esta solução também apresenta limitações quanto aos conhecimentos que pode fornecer. Decerto também reconhecia a multiplicidade dos possíveis recortes ou métodos discriminativos para as experiências de terceira pessoa. Jamais lhes rejeitou a utilidade ou mesmo a vantajosa associação entre as distintas perspectivas teóricas e plataformas de trabalho que daí poderiam surgir.

... but we must realize also that psychology cannot hope to approach this scientific ideal; instead it must engage in many promising approaches. These, indeed, open up perspectives, but their ideal solution remains infinitely remote. (Jaspers, 1968, p. 1315) 
Assim, para o autor, a opção por se dirigir àquilo que se afigura - e como se afigura - ao paciente, bem como recorrer a parâmetros objetivos de descrição, não se trata de uma recusa à fertilidade de outras propostas de abordagens psico(pato)lógicas. Antes, visava garantir à psicopatologia a ancoragem empírica em dados passíveis de observação por qualquer um, e não em construções que, embora coerentes, tenham natureza teórica. Evidentemente, poder-se-ia alegar que mesmo os elementos externos por ele privilegiados têm sua realidade ontológica tão questionável quanto a de qualquer elemento teórico - sendo dependentes do observador para selecioná-los e organizá-los numa construção pessoal do "estado de coisas”. Todavia, ainda que não seja absolutamente evidente se este era o propósito de Jaspers, chamamos atenção para o fato de que o privilégio concedido aos tais descritores "externos” resulta em construir-se a psico(pato)logia sobre a plataforma da linguagem comum de determinada forma de vida ou sociedade. Os símbolos usados para elaboração da psico(pato)logia, desta forma, passariam a ser correspondentes aos referenciais utilizados na vida comum. Recairia sobre a intersubjetividade e, isomorficamente, ao modo de pensarmos e ao feitio habitual da vida de relação, a estrutura da psico(pato)logia.

Note-se que compreender a fenomenologia jasperiana como mera atividade descritiva e de delimitação das ocorrências psíquicas não reflete todo seu valor. Fosse apenas isto, e utilizando os parâmetros objetivos que recomenda, não se distinguiria das abordagens psicológicas objetivas que condenava. De fato, estas primeiras etapas apenas sinalizam, na interface entre as linguagens dos dois indivíduos (observador e paciente), a região para a qual o primeiro estará direcionando sua capacidade empática e a partir da qual elaborará, com linguagem explícita, a “compreensão empática”. Todavia, em que pese ter reservado um espaço privilegiado para a empatia em seu modelo, um entendimento apenas parcial de sua proposta ainda poderia tornar estranho lhe creditarmos o mérito de ter amalgamado a desejada cientificidade à preservação da subjetividade no foco da psico(pato)logia. Isto porque, até este ponto, tal subjetividade surgiria apenas como “conclusão” de uma técnica objetiva e restrita às expressões exteriores do psíquico. Contudo, chamamos atenção para um ponto que parece negligenciado e que acreditamos salvaguardar Jaspers desta aparente falta que tal malentendimento poderia sugerir. O caso é que a fenomenologia não foi concebida para ser tudo o que era desejável para a “psico(pato)logia”, mas para possibilitála a posteriori. A fenomenologia jasperiana não deve ser acusada de encobrir a própria omissão à “subjetividade como objeto de estudo” por meio de sua apresentação como "resultado", pelo simples fato de que a fenomenologia não visa ser uma metodologia de "tratamento" completo e definitivo aos fatos psico(pato)lógicos. Almeja apenas apontá-los de modo seguro. Ela apenas diz quais são, pelo método explícito que descreveu, para posterior articulação. Assim, 


\begin{tabular}{cccccc|l}
$R \quad E \quad V$ & I & T A & \\
LATIN O A M ERIC A N A & \\
DE PSICO OPATO LOGIA & \\
F U N D A M E N T A L & \\
anO VIII, & n. 4 , dez/2005 & \\
\hline
\end{tabular}

a fenomenologia seria uma ferramenta concebida para levar-nos de um ponto em que ainda não se dispõe de uma linguagem explícita para tratamento ao fenômeno psico(pato)lógico até o ponto em que estes estão devidamente caracterizados e permitindo não mais apenas empatia, mas uma “compreensão empática”. Exatamente por não incluir o estabelecimento de relações entre os elementos psíquicos, mas simplesmente “apreendê-los”, Jaspers usou da fenomenologia como intercambiável pelo termo "compreensibilidade estática”.

Por fim, já estava previsto por Jaspers, numa etapa seguinte, o desejável estabelecimento das “conexões compreensíveis”, segundo as quais os elementos derivados da aplicação da fenomenologia seriam encadeados. Esta sim uma "psico(pato)logia” - nomeada "compreensibilidade genética” - seria o clímax para o qual seu método foi concebido. ${ }^{3}$ Neste caso positivamente, tendo seus papéis legitimados por esta etapa que segue, a empatia e a "compreensão empática" poderiam, sem caracterizar ilusão, permanecer como encerramento do método fenomenológico.

\section{O esteio da fenomenologia jasperiana}

O exame dos antecedentes teóricos de Jaspers nos auxilia em compreender sua fenomenologia e garante-nos as conclusões e comentários aqui tecidos.

Certamente, uma das influências centrais à psicopatologia, como explorada por Jaspers, foi Wilhelm Dilthey e sua defesa à valorização de uma perspectiva descritivo-analítica para as ciências humanas, em detrimento aos enfoques teóricoexplicativos (Jaspers, 1994; Dilthey, 1977).

Na concepção de Dilthey “desenvolvimento” e “estruturação” psicológica consistiriam em aspectos indissoluvelmente relacionados. Para o filósofo, o desenvolvimento psíquico não resultaria em “saltos” entre níveis psicológicos, ou em uma organização psicológica hierarquizada. Em vez disso, sustentava uma idéia de consciência como sistema e pressupunha a manutenção de uma relação de

3. Apesar de Jaspers jamais ter perdido de vista a idéia de que o ideal da psicopatologia seria o estabelecimento das conexões compreensíveis, sempre foi, por outro lado, muito claro em distinguir a fenomenologia daquilo que chama de "compreensibilidade genética". Segundo Jaspers "... phenomenology has nothing to do with genesis of psychic phenomena. Though its practice is a prerequisite for any causal investigation it leaves genetic issues aside (...)”. Ainda, para Jaspers, “... phenomenology must kept separate from what we call 'genetic understanding' of psychic events, i.e. the comprehension of their meaningful relationships”. (Jaspers, 1968, p. 1322). 
influência mútua entre os diversos aspectos do psiquismo (afetivo, volitivo, cognitivo, representativo...). Deste modo, para Dilthey, não apenas os diversos aspectos da vida psíquica - por fazerem parte de uma unidade dinâmica - estariam impedidos de ser compreendidos em isolado, como também isto repercutia em uma distinta exigência epistêmica para a psico(pato)logia quando a comparamos às ciências naturais. Dilthey era avesso aos tratamentos meramente metafísicos ou idealistas à psicologia, mas repudiava igualmente as tentativas positivistas de isolar as ocorrências psíquicas ou reduzi-las. Não apenas sugeria que o emprego de tais mecanismos negligencia a continuidade da experiência e apreende os fatos psíquicos de maneira deformada, como também propunha claramente que a determinação do sentido de cada evento se pode dar apenas observando e visando a análise concomitante do todo psicológico. Justificava-se, assim, para este autor, o insucesso da psicologia experimental, da psicologia associacionista e da psicologia das faculdades. Entenda-se, portanto, que, ao valorizar uma perspectiva "descritivo-analítica”, o termo "descritivo" toma, para Dilthey, um sentido que é diverso do "explicativo/sintético" que tem nas ciências naturais. Nestas últimas, descrever faz parte de um processo de acumulação progressiva das informações, conforme surjam, com o fim de obtenção de hipóteses, teorias ou leis de caráter inclusivo, explicativo e preditivo para eventos posteriores. Por outro lado, nas ciências humanas e psicologia, o termo "descritivo" estaria sempre associado a um fim analítico. Isto é, já que na psicologia sempre se partiria da suposição do todo da experiência, o termo "descritivo" significaria a "determinação e fixação de suas partes”. Não lhe passava à margem o problema de que, defendendo uma concepção integrada e dinâmica dos componentes psíquicos, pareceria inadequada a "descrição" e "fixação das partes" como princípio da exploração psicológica. Todavia, em seus estudos posteriores (The Understanding of Other Persons and Their Expressions of Life, 1910), justamente onde é acusado de abandonar a psicologia descritiva em favor de uma hermenêutica, surge uma possibilidade de resposta a este problema. Ao examinar as diferentes modalidades de "expressão" e os distintos níveis de "compreensão" das mesmas, aponta a "vida comum" como o espaço do qual deve derivar os recortes conceituais e significados para o início do processo de entendimento psicológico; os mais simples e superficiais entendimentos sobre as mais ostensivas "expressões" humanas seriam dados em referência aos acordos lingüísticos de uma "forma de vida" ou sociedade. Tais conceitos e significantes poderiam bem corresponder ao suporte preferencialmente utilizável para o princípio do processo de descrição.

Dilthey desejava um status científico para a psicologia, e não filosófico; mas para o êxito deste projeto via como necessário trazer seu objeto de estudo para o "nível” e para as "condições" em que realmente existe: o "nível da experiência" e a "condição de objeto integrado ao todo da experiência”. De fato, Dilthey 


\section{$\begin{array}{lllllll}R & E & V & \text { I } & S & T & A\end{array}$ \\ LATIN O AMERICANA \\ DE PSICOPATOLOGIA \\ F U N D A M E N T A L \\ ano VIII, n. 4, dez/2005}

propunha, inclusive, que as ciências humanas dispunham de uma valiosa vantagem em relação às ciências naturais, a saber, que nas ciências naturais a relação entre os fenômenos jamais é dada por si mesma ou a priori, mas necessita sempre do observador. Este apenas poderia, por necessidade, relacioná-los por meio de hipóteses, mas jamais conferindo sentido a esta articulação. Estas formulações e articulações, para os fenômenos psicológicos, seriam dispensáveis no entendimento de Dilthey, que percebia como já dada, na própria experiência, toda a articulação compreensível entre os fatos psíquicos. Ainda, havendo em cada um de nós as mais variadas ordens de conexões psicológicas - com preponderância de tipos variando entre os indivíduos -, a transposição destas conexões psicológicas compreensíveis para a terceira pessoa seria o instrumento a ser usado para a compreensão do processo que vive. Para os fenômenos naturais, a impossibilidade desta transposição exigiria as formulações de hipóteses e explicações, jamais dotadas de sentido intrínseco ou compreensibilidade como nos permitem a psicologia e as ciências humanas em geral. Todavia, na medida em que Dilthey assumia a persistente influência mútua entre as qualidades psíquicas, também compreendia que a configuração psicológica de cada instante sobrepunha as características mais marcantes àquelas mais tênues. Presumindo esta sobreposição e o encobrimento de “partes” do todo psicológico, ele rejeitou a introspecção como método confiável para o entendimento sobre si mesmo. A evidência disto seria que, não raro, apenas ao observarmos outras pessoas perceberíamos certos aspectos psicológicos presentes em nós mesmos. Como conseqüência do questionamento à validade da introspecção e da autoridade subjetiva (de primeira pessoa) sobre as configurações psicológicas próprias, fica claro que, para Dilthey, também não poderia ser válida a utilização das comunicações destas introspecções para o entendimento psicológico sobre a terceira pessoa. No entendimento de Dilthey, não era possível uma situação de completa isenção do examinador em relação ao interlocutor resultar em conhecimento sobre o funcionamento psicológico deste último, já que suas introspecções sempre necessitam ter sua validade sujeita à verificação. Isto se daria pela comparação e integração da experiência interna - apreendida pela introspecção e comunicada ao examinador (inner experience) - aos comportamentos e observações deste último sobre a vida de relação do primeiro, compondo um quadro mais completo da configuração do psiquismo e suas manifestações. Neste entremeio das evidências objetivas - e acessíveis à terceira pessoa - com a experiência subjetiva comunicada, residiria, para Dilthey, a possibilidade de uma ciência psicológica (Makkreel, 1977).

Assim, devemos observar que muitos dos pontos defendidos por Dilthey são explicitamente expressos na psicopatologia jasperiana: 1) a idéia de articulação entre os elementos psíquicos e sua impossibilidade de apreensão como elemento 
isolado; 2) seu entendimento crítico sobre o contínuo ciclo de ressignificação do todo a partir dos elementos e vice-versa; 3) a não aceitação incondicional das comunicações derivadas da introspecção e o papel definitivo do examinador em integrar coerentemente estas introspecções aos fatos exteriores; 4) a descrição como princípio da exploração psico(pato)lógica e o posicionamento ateórico do examinador nesta tarefa; entre outros itens concordantes. De fato, parece muito pertinente o comentário de Jenner et al. (1986) de que, fora conhecida a obra de Dilthey no meio psiquiátrico, muito do trabalho de Jaspers teria sido redundante.

\section{O que não é a fenomenologia jasperiana}

Ao longo do século XX, para diferentes autores, o termo fenomenologia encerrou diferentes concepções onto-epistemológicas e técnicas apreensivoinvestigativas. Uma das implicações da multiplicidade de significados do termo é que ao se falar sobre a psicopatologia fenomenológica jasperiana, freqüentemente, o que vem à mente difere entre os indivíduos conforme suas formações. De maneira geral, o berço acadêmico dos não experts que se deparam com a fenomenologia de Jaspers é um importante deformador das primeiras impressões ou de suas conclusões superficiais sobre o que realmente pretendia aquele autor - fato que supomos agravado pela já mencionada brevidade e imprecisão com que o texto jasperiano mais difundido sobre o assunto o trata. Assim, o que se entende por fenomenologia não é o mesmo em Husserl que em Heidegger, Sartre e Merleau-Ponty; ou ainda, o mesmo que para Binswanger ou Blankenburg. Tampouco, qualquer um que, em razão de seu background, lida com algum destes modelos, daí pode subsumir a fenomenologia jasperiana. Ao fazermos estas distinções não propomos que sua fenomenologia perde em legitimidade, devendo ser avaliada segundo suas próprias virtudes e limitações. Tampouco aqui ambicionamos nos estender ou definir com precisão os diversos significados do termo fenomenologia. O propósito deste esclarecimento é, isto sim, evitar que desavisados, conhecendo o significado do termo fenomenologia em Husserl e na tradição fenomenológico-existencialista, e ignorando o trabalho de Jaspers, tomem o último por aspecto das primeiras.

Uma primeira relação mais ordinária e firmemente estabelecida, embora sujeita a contestações, é entre a fenomenologia de Jaspers e a husserliana. Entre as análises comparativas, relacionando-as, visões como as de Walker (1994; 1995) e Berrios (1992), que convincentemente negam a existência de similaridades significativas entre as mesmas, e que recusam Husserl como precursor intelectual da fenomenologia jasperiana, são exceções. Dificilmente, porém, esta conexão não 


\section{$\begin{array}{lllllll}R & E & V & I & S & T & A\end{array}$ \\ LATINOAMERICANA \\ DE PSICOPATOLOGIA \\ F U N D A M E N T L L \\ ano VIII, n. 4, dez/2005}

teria sido admitida e difundida na literatura. Isto porque o próprio Jaspers era explícito em reconhecer débito para com Husserl e aquilo que considerava ser uma "psicologia descritiva” na essência da fenomenologia daquele autor.

As a method I adopted and retained Husserl's phenomenology - which he initially called "descriptive psychology" - discarding only its refinement to essence perception. (Jaspers, 1994)

Ao tomar a fenomenologia de Husserl por uma psicologia descritiva, e considerando imperativo o tratamento à psicologia com rigor metodológico e cientificidade - aspecto este em que Jaspers também se alinhava às expectativas de Dilthey -, fazia bastante sentido que o próprio Jaspers admitisse sua filiação teórica àquele primeiro autor.

Foi exatamente a esta desejável cientificidade para a psicologia e psicopatologia que Jaspers pensava que Husserl abrira as portas com suas "Investigações lógicas”. A despeito de posteriormente ter rejeitado as idéias contidas em "Philosophy as Rigorous Science" - obra seguinte de Husserl, mais unanimemente entendida como uma proposta de abordagem eidética da consciência, mas não empírica, ${ }^{4}$ e considerada por Jaspers como uma traição de Husserl a sua atitude científica inicial - Jaspers persistiu reconhecendo a influência deste "primeiro Husserl” e sua suposta psicologia descritiva, sobre toda sua própria fenomenologia. Ironicamente, e contrariamente ao entendimento de Jaspers e de muitos outros estudiosos, em nenhuma destas obras Husserl olvidava fazer da fenomenologia um método de acesso empírico à experiência psicológica de outrem ou uma psicologia descritiva. Em verdade, o próprio Husserl veio oportunamente a repudiar tal entendimento sobre sua proposta (Berrios, 1993; Walker, 1994a). Além do equívoco sobre o propósito do eidetismo em Husserl, é também comum a superposição forçada entre o método de “epoché” - a suspensão da assumpção de qualquer modelo, idéia, relação entre o mundo e a consciência, e mesmo de qualquer realidade externa à consciência; utilizada como dispositivo pelo transcendentalismo deste autor - e o posicionamento pré-teórico de Jaspers. Enquanto, com o método citado, Husserl buscava um modo de abordar e estudar a consciência como objeto em si, e com aquilo que lhe é

4. Embora a atitude metodológica eidética, sugerida tanto em Logical Investigations quanto em Philosophy as Rigorous Science - buscando a passagem dos elementos particulares para as essências ou universais -, possa ser interpretada e até empregável como recurso empírico de conhecimento (como feito por Jaspers) não parece ser este o propósito do eidetismo em Husserl, já que o autor propõe sua aplicação também a situações hipotéticas ou experimentos mentais. Assim, trata-se mais de um recurso para o desvelamento das possibilidades lógicas, das possibilidades de conhecimento e da estrutura da consciência. 
característica exclusiva e independente do mundo (a intencionalidade), Jaspers o aplicou não como instrumento de detecção da estrutura do "puramente psíquico", mas do "psico(pato)lógico" como experimentado e sem interpretações. Diferente do proposto por ele, portanto, a fenomenologia husserliana clássica se inseria num sistema filosófico que integrava os aspectos lógicos, lingüísticos, ontológicos e epistemológicos, onde cumpria o fim de estudar a estrutura da experiência ou consciência (Embree, 1998; Smith, 2003). De outro lado, ao considerarmos a característica central da tradição fenomenológico-existencialista - nela incluídos Heidegger, Sartre e Merleau-Ponty - a saber, a recusa à possibilidade de entendimento do "ser" ou da existência se desconsiderado o mundo que cerca o homem, observemos que, embora nisso possam ser encontradas semelhanças em relação aos trabalhos de Jaspers (particularmente os de sua carreira filosófica), para estes autores, as modalidades de "encarnação" (embodiment) ou de "ser-nomundo" (being-in-the-world) tendem a ser exploradas por meio de categorias que não necessariamente nos são apresentadas pela consciência do indivíduo, mas sim derivadas das observações e de sua aplicação pelo investigador (ibid.). Assim, portanto, a atitude pré-teórica exigida por Jaspers tem papel menos crucial. Entre outras categorias empregadas podemos citar a temporalidade, a corporeidade, a identidade e o papel social. Mais ligados a esta última tradição, e não tanto aos estudos psicopatológicos de Jaspers, estão autores importantes na história da psicopatologia fenomenológica psiquiátrica, como Blankenburg e Binswanger, e autores modernos como Kraus, Parnas, Bovet e Wiggins.

\section{Conclusão}

A fenomenologia jasperiana é, de fato, inclusive segundo palavras do próprio Jaspers, uma "psicologia descritiva”. Mas não o é no sentido pejorativo em que a expressão é habitualmente utilizada pelos críticos. A etapa descritiva seria apenas a inicial e para ancoragem, para o atingimento do fenômeno subjetivo. Tributária das antecipações de Dilthey, a fenomenologia de Jaspers transita entre a psicologia subjetiva, que busca o entendimento psicológico em si mesmo e como é vivido (mas que não é tangível ou externamente observável de maneira imediata), e uma psicologia objetiva (que embora se ofereça a métodos próprios das ciências naturais, não nos ensina nada sobre o psiquismo e como a ele nos referimos nas relações intersubjetivas). Garantir a conexão entre os fenômenos psicológicos e referentes externos que pudessem validar-lhes a presença em diferentes situações seria, para Jaspers, o modo de possibilitar o exame científico das relações compreensivas entre aqueles fenômenos que não se deixam observar pela terceira 


\section{$\begin{array}{lllllll}R & E & V & \text { I } & S & T & A\end{array}$ \\ LATIN O AMERICANA \\ DE PSICOPATOLOGIA \\ F U N D A M E N T L L \\ ano VIII, n. 4, dez/2005}

pessoa. Assim, a fenomenologia surge, para ele, como um método envisado para responder às necessidades de cientificidade para a psico(pato)logia e, ao mesmo tempo, atender ao imperativo de não exclusão ao verdadeiro objeto de estudo destas disciplinas, a experiência subjetiva.

Por fim, cabe ressaltar que o notável papel de Jaspers, e de suas idéias para a psicopatologia e psiquiatria, muitas vezes é tomado como critério de inviolabilidade à autoridade de seus escritos. Entretanto, não apenas o método fenomenológico, do modo que concebeu, não é livre de tensões internas, como também não se pode dizer que a psicopatologia que nos legou está concluída e plenamente de acordo com o modelo que sugeriu. Conhecedores de que o projeto jasperiano de psicopatologia não se encerrava na delimitação dos objetos de estudo (fenômenos) nos casos individuais, mas também previa a definição dos “tipos ideais” de manifestações pela observação e comparação dos casos sucessivos e, inclusive, ambicionando a utilização destes tipos ideais para a elaboração de uma ciência e modelo teórico geral para a psicopatologia -, fica-nos o pertinente questionamento sobre o quanto realmente é razoável a expectativa de engendramento entre as finalidades particular e geral do método (Broome, 2002). Em que medida, após a indução dos recortes conceituais padrões, sua utilização não estará sempre sacrificando elementos cruciais ao entendimento do caso individual ${ }^{5}$ Além disso, em que pese termos herdado, da psicopatologia clássica, uma diversidade de recortes fenomenológicos e definições - aí incluídos muitos daqueles descritos pelo próprio Jaspers - estranhamente o autor não demonstra e nem sugere tê-los derivado da observação de uma série de casos, mas sim de casos individuais. Deste modo, cabe indagar, inclusive, sobre o quanto nossa matriz psicopatológica talvez tenha sido conformada e ainda venha trabalhando, em decorrência da tradição, por objetos malcaracterizados segundo o método fenomenológico (Spitzer, 1988). Se estes questionamentos estiverem na trilha correta, faria sentido afirmarmos que, preservado o reconhecimento ao método proposto por Jaspers, a psicopatologia fenomenológica, desde suas bases - a adequada demarcação e definição dos seus sinais e sintomas - ainda se encontra por ser edificada.

5. Embora não nos estendamos quanto a este ponto, observamos que tal tensão entre a generalidade e a individualidade não é problema exclusivo da psicologia e psicopatologia, mas da ciência como um todo, talvez se ressaltando nestes campos em virtude da complexidade da composição de cada fenômeno externalizado. Ademais, levantamos a "linguagem comum" e o "modo comum de vida" como possíveis pontos de apoio - talvez até visualizados pelo próprio Jaspers - para garantir ao menos um grau razoável de superposição entre a delimitação dos objetos de estudo nos patamares geral e particular. 


\section{Referências}

Berrios, Germán Elías. Phenomenology and Psychopathology: Was There Ever a Relationship? Comprehensive Psychiatry. Estados Unidos, v. 34, n. 4, p. 213-20, 1993. Broome, Matthew. Explanatory Models in Psychiatry. The British Journal of Psychiatry. Reino Unido, v. 181, n. 4, p. 351-2, abr./2002.

Dilthey, Wilhelm. Ideas Concerning a Descriptive and Analytical Psychology. In: Zaner, Richard M. e Heiges, Kenneth L. (orgs.). Descriptive Psychology and Historical Understanding. The Netherlands: Martinus Nijhoff, The Hague, 1977. p. 21120.

Embree, Lester. Phenomenological Movement. In: Routledge Encyclopedia of Philosophy. London: Routledge, 1998. p. 333-43.

HoENIG, John. Karl Jaspers. International Journal of Neuropsychiatry, v. 2, n. 4, p. 3513, 1966.

JASPERs, Karl. The Phenomenological Approach in Psychopathology. British Journal of Psychiatry. Reino Unido, v. 114, p. 1313-23, nov./1968 (originalmente publicado em Zeitschrift für die Gesamte Neurologie un Psychiatrie, 1912).

Origins in Scientific Research: An Autobiographical Account. In: EHRLICH, Edith; Ehrlich, Leonard E. e Pepper, George B. (eds.). Karl Jaspers Basic Philosophical Writings. New Jersey: Humanities Paperback Library, 1994. p. 5-8.

p. VII.

Prefácio à Sétima Edição. In: Psicopatologia geral. São Paulo: Atheneu, 2000.

Introdução. In: Psicopatologia geral. São Paulo: Atheneu, 2000. p. 11-70.

Jenner, Alec et al. The Negative Effects on Psychiatry of Karl Jaspers' Development of Verstehen. Journal of the British Society for Phenomenology. Reino Unido, v. 17, n. 1, p. 52-71, jan./1986.

Kraus, Alfred. Phenomenological-Anthropological Psychiatry. In: Henn, Fritz A. et al (eds.). Contemporary Psychiatry. New York: Springer-Verlag, 2000. cap. 21, p. 339-55.

How can the Phenomenological-Anthropological Approach Contribute to Diagnosis and Classification in Psychiatry? In: Fulford, Bill et al. (eds.). Nature and Narrative. New York: Oxford University Press, 2003. cap. 13, p. 199-215.

Makkreel, Rudolf A. Introduction. In: Heiges, Kenneth L. e Zaner, Richard M. (eds.) Descriptive Psychology and Historical Understanding. Holanda: Martinus Nijhoff, The Hague, 1977. p. 3-20.

Mundt, Christoph. Karl Jaspers. American Journal of Psychiatry. Estados Unidos, v. 150, n. 3, p. 1244-5, 1993. 
Parnas, Josef e Zahavi, Dan. The Role of Phenomenology in Psychiatric Diagnosis and Classification. In: MAJ, Mario et al. (eds.). Psychiatric Diagnosis and Classification. West Sussex, Reino Unido: John Wiley \& Sons Ltd, 2002. cap. 6, p. 137-62.

Schwartz, Michael Alan e Wiggins, Osborne P. Phenomenological and Hermeneutic Models: Understanding and Interpretation in Psychiatry. In: RAdDEN, Jennifer. The Philosophy of Psychiatry. New York: Oxford University Press, 2004. cap. 24, p. 351-63.

Sмiтh, David Woodruff. Phenomenology. In: Zalta, Edward N. (ed.). The Stanford Encyclopedia of Philosophy Online, 2003. Acesso em: 20 de maio de 2005. URL: $<$ http://plato.stanford.edu/archives/win2003/entries/phenomenology>.

Stanghellini, Giovanni. The Genealogy of Psychopathology. In: Disimbodied Spirits and Deanimated Bodies. New York: Oxford University Press, 2004, cap. 1, p. 25-44.

Spitzer, Manfred. Psychiatry, Philosophy and Description. In: Spitzer, Manfred et al. (eds.). Psychopathology and Philosophy. Berlim: Springer-Verlag. p. 3-18.

Walker, Chris. Karl Jaspers and Edmund Husserl - 1: The Perceived Convergence. Philosophy, Psychiatry and Psychology, v. 1, n. 2, p. 117-34, jun./1994.

Karl Jaspers and Edmund Husserl - 2: The Divergence. Philosophy, Psychiatry and Psychology, v. 1, n. 4, p. 245-65, dez./1994.

Karl Jaspers and Edmund Husserl - 3: Jaspers as a Kantian Phenomenologist. Philosophy, Psychiatry and Psychology, v. 2, n. 1, p. 65-84, mar./1995.

Karl Jaspers and Edmund Husserl - 4: Phenomenology as Empathic Understanding. Philosophy, Psychiatry and Psychology, v. 2, n. 3, p. 247-66, set./1995 